\title{
Genetic Endowments, Parental and \\ Child Health in Rural Ethiopia
}

CSAE WPS/2003-10

\author{
Bereket Kebede \\ Wellbeing in Developing Countries (WeD), ESRC Research Group, \\ University of Bath and \\ Centre for the Study of African Economies, Oxford University
}

August 2003

JEL Classification: D13, I12

Key words: Ethiopia; child health; intra-household allocation; genetic influences in health

Acknowledgement: This working paper draws from my DPhil thesis. I am very grateful to my supervisors Paul Collier, Pramila Krishnan, Jan Gunning and Marcel Fafchamps for their intellectual guidance at different stages of my studies at Oxford.

Corresponding Author: Bereket Kebede, Wellbeing in Developing Countries (WeD), ESRC Research Group, 3 East 2.10, University of Bath, Bath, BA2 7AY, United Kingdom; Email address: b.kebede@bath.ac.uk 


\title{
Genetic Endowments, Parental and
}

\author{
Child Health in Rural Ethiopia
}

\begin{abstract}
This paper examines the determinants of child health in rural Ethiopia for the period 1994-97 using height-for-age $\mathrm{z}$-scores as measures of long-term health. The panel nature of the data helps to control for community, household and individual level heterogeneity. Unlike most previous studies, the influence of parental health on children is examined. In addition, the role of genetic endowments in the relationship between child and parental health is analysed. Unlike most studies in the health literature, no significant correlation between children's health and per capita expenditures is found. This reinforces the widespread suspicion that most income coefficients in the literature are biased upwards due to correlation between unobservable heterogeneity and income levels. But the height of parents is highly significant in all specifications. Even though most prices are not significant, the prices of food items that are mostly consumed by children are significantly and negatively related to child health. Birth order has a significant impact on the health of children; older children are taller than their younger siblings. Female children have better height-for-age z-scores than males. Since the health of children deteriorates with their age, deprivations in later years are probably more important than during pre- or neo-natal periods. This seems to be confirmed by the statistical insignificance of a dummy variable that identifies children born in a year when the household lost substantial harvest due to drought. The number of siblings of the wife significantly and negatively affects the health of children; but that of the head is not significant. As females control the management of housework and food preparation, their siblings probably compete with their children more than that of the husband's. Years of marriage, probably reflecting stability in marriage, have a beneficial impact on child health. Altitude has a significant negative impact on the health of children. Finally, correlations between child and parental health are mainly explained by genetic inheritance than by behaviour. In an environment where there are no radical differences in the nutritional and disease environments of parents and children, the importance of genetic endowments in determining child health should not be underestimated.
\end{abstract}




\section{Genetic Endowments, Parental and Child Health in Rural Ethiopia}

\section{Introduction}

The effects of income and other socio-economic factors on health in general and child health in particular have received much attention in the literature. An important limitation of most of the research in this area is the inability to control for unobserved heterogeneity of individuals. The correlation between the individual level error terms and the variables included in the analysis leads to biased estimates. People are living in diverse communities and households; individuals differ from one another in many respects that are not directly observed by researchers. The use of panel data and estimation techniques that control for different levels of heterogeneity go a long way in mitigating these problems.

In addition to the problem of unobserved heterogeneity, most studies on child health and its socio-economic determinants do not control for parental health. This is partly driven by lack of data; most surveys that collect information on child health do not have information on parental health. Parental health influences child health either through sharing the same genetic endowments and/or through other behavioural effects.

This paper examines the determinants of child health in rural Ethiopia for the period 1994-97. ${ }^{1}$ In particular, the height-for-age z-scores of children are used as measures of long-term health. The panel (cross section-time series) nature of the data enables us to control not only for community and household but also individual level heterogeneity. In addition, since information on the health of parents - at least one of the parents - is available, the influence of parental health on children is examined. Hence, both problems that plague most of the research on child health mentioned above are tackled.

In addition to controlling for the different levels of heterogeneity and examining the impact of parental health, this paper further analyses the role of genetic endowments in the relationship between child and parental health. This is a novel contribution to the economic research on child health.

\footnotetext{
${ }^{1}$ The data from the Ethiopian Rural Household Survey are used. For a description of the data see Kebede (2003).
} 
Unlike most studies in the health literature, no significant correlation between children's height-for-age z-scores and per capita expenditures is found; even though a positive coefficient is generated by OLS, no significant correlation remains when individual level heterogeneity is controlled for. This reinforces the widespread suspicion that most income coefficients in the literature are biased due to correlation between unobservable heterogeneity - one of which is the health of parents - and income levels. On the other hand, the height of parents is highly significant in all specifications. Even though most prices are not significantly correlated to child health, the prices of food items that are mostly consumed by children are significantly and negatively related to child health. Birth order has a significant impact on the health of children; older children are taller than their younger siblings. Female children have better height-for-age z-scores than males. Since the health of children deteriorates with their age, deprivations in later years are probably more important than during preor neo-natal periods. This seems to be confirmed by the statistical insignificance of a dummy variable that identifies children born in a year when the household lost substantial harvest due to drought.

The number of siblings of the wife significantly and negatively affects the health of children; but that of the head are not significant. As females control the management of housework and food preparation, their siblings probably compete with their children more than that of the husband's.

Years of marriage probably reflect stability in marriage that can be a consequence of better matching in the marriage market; stable marriages in turn have a beneficial impact on child health.

Even though altitude is one possible important factor that affects health, almost all economic studies have neglected it. The empirical results indicate that altitude has a significant negative impact on the health of children.

Apart from the analysis of factors affecting the health of children, this paper focuses on the correlation between child and parental health. The empirical findings, with some exceptions, show that the correlation between child and parental health is mainly explained by genetic endowments rather than by behaviour. In an environment where there are no radical differences in the nutritional and disease environments of parents and children, the importance of genetic endowments in determining child health should not be underestimated. In addition, genetic endowments are expected to play a more important role in an environment with low 

cross-sectional variations in the nutritional status and disease conditions of households at different levels of income as the case is in rural Ethiopia.

This paper is structured in the following way. The next section briefly reviews the recent literature on child health. Section 3 looks at measurement issues and presents some descriptive results. The main empirical findings are presented in Section 4. Section 5 concludes.

\section{Child Health, Income and Other Determinants: A Brief Review of the Literature}

Child health is affected by a host of economic, biological and social factors. The literature has extensively examined the effect of income, one of the important economic variables affecting child health. First, income levels affect the amount of resources households devote for nurturing children. Second, health-related behaviour of people (like smoking, alcohol consumption, healthcare, etc.) is usually systematically correlated with levels of income. Third, in addition to the absolute levels of income, health is affected by income inequality - particularly in industrialised countries. Lower ranks in the distribution of income probably raise psychosocial stress that negatively affects endocrine processes and immunity (Smith, 1999).

Even though the evidence is mixed, most studies have found a positive impact of income on health - both child and adult health. Thomas, Lavy and Strauss (1996) found that higher incomes are associated with better health of children and adults in Cote d'Ivoire - measured respectively by child height and weight and adult body mass index. Both total household income and wealth are positively related to self-reported health status in the US (Smith, 1999). The same is true if the health of US children is measured by specific ailments (Case, Lubotsky and Paxson, 2001). McCunn et al. (2001) found that the higher psychological morbidity among children of lone-mothers was in fact a consequence of income and other socio-economic effects (benefit receipts, housing tenure and maternal education) in the $\mathrm{UK}^{2}{ }^{2}$ Most of the sixteen studies reviewed in Benzeval and Judge (2001) found positive association between health and income levels. In addition, most studies show that income levels are more important than income changes.

\footnotetext{
${ }^{2}$ For results contradicting this finding (for Canada) see Curtis et al. (2001).
} 
The association between income and health may not be linear. Smith (1999) using self-reported health status found strong non-linearity where the impact is the highest at lower income levels; a unit increase in income increases the health status of the poor more than that of the rich.

But in contrast to the above results, Suwal (2001) found only a weak effect of income on infant mortality in Nepal. Even though average and current incomes affect different aspects of children's health in Canada, neither is correlated with emotional problems (Curtis et al., 2001).

The age of children strongly influences the effect of income on health. Jensen and Richter (2001) found that the difference in stunting of children between the poorest and richest quartiles is greatest at the youngest ages. Deprivation during pregnancy, selective mortality - where the less healthy among the poor die earlier and hence are not observed - and/or catching-up by the poorer children can be possible explanations. But Case, Lubotsky and Paxson (2001) found just the opposite for the US; income is more protective of children's health at older ages for almost every ailment considered. The latter result makes sense if older children are more sensitive to environmental factors (Adams, Madhavan and Simon, 2002) and income makes a significant difference in shaping these factors. In addition to the reasons mentioned, the result for Russia may be a reflection of the weakness in the maternal health and childcare infrastructure of the country as compared to the US.

An important estimation problem that plagues studies on the relationship between health and income is endogeneity. If both health and income levels are affected by factors unobserved by researchers the estimated correlation will be spurious. For example, genetic endowments and social background may strongly affect both health and income-earning potential of individuals. If studies do not control for the genetic endowments and social background (most studies don't), the income coefficient will also capture their additional effects biasing estimates. One way of overcoming this problem is to consider only exogenous (or unexpected) income. Lindahl (2002) uses the monetary lottery prizes of Swedish households as a measure of exogenous income. Surprisingly, the coefficients from Lindahl (2002) are very similar in magnitude to those from studies using traditional income measures. The results imply that studies that use total income may not be as biased as is usually assumed. 
In addition to the endogeneity problem, that health is a stock accumulated over longer periods of time also complicates matters. This implies 'permanent' rather than current levels of income are more important determinants of health. Case, Lubotsky and Paxson (2001) in their study of child health using specific disabilities in the US found that health is closely associated with long-run average household income. Curtis et al. (2001) found a similar result for Canada. In addition, family incomes before the birth and at different ages of the child are all equally correlated with children's current health status in the US (Case, Lubotsky and Paxson, 2001). The long-run and lagged relationship between income and health is also emphasised by almost all the sixteen studies reviewed in Benzeval and Judge (2001); the studies used measures of income that precede health outcomes.

The emphasis on a life-course perspective on individuals' health is a growing trend in the literature (Benzeval and Judge, 2001). Lynch, Kaplan and Salonen (1997) used information on the socio-economic status of individuals in Finland at three stages of the lifecycle: during childhood (measured by parental socio-economic status at the age of 10) adolescence (measured by education) and adulthood (measured by occupation). They found that adult behaviours and psychological orientations are patterned by childhood socio-economic status.

In addition to experiences during childhood, conditions during pregnancy and during infancy are important (pre- and peri-natal conditions). The health of an embryo depends on a reliable supply of nutrients and oxygen and the size of the uterus. Lack of nutrients or oxygen in the womb affects cell division and development of organs that can 'programme' the body making it susceptible to later life diseases (Smith, 1999). Short maternal stature and low pre-pregnancy body mass index affect the condition of pregnancy. An important indicator of prenatal deprivation, which results in intrauterine growth retardation (IUGR), is low birth weight. Low birth weight reflects the standard of mother- and child-care practices and is a consistent predictor of wasting prevalence for children under five in Asia, Africa and Latin America (Fernandez, Himes and de Onis, 2002; see also Strauss and Thomas, 1995). The importance of prenatal factors is also illustrated by the findings of Jensen and Richter (2001) for Russia; when indicators for the intake of calories, protein and vitamins during pregnancy are included, post-natal socio-economic variables were no more statistically significant. Studying the effects of pre- and post-natal behaviour is further 
complicated because parents' health-related actions may differ before and after pregnancy/childbirth (Persson, 2001).

The importance of prenatal conditions has led some to the idea of 'biological programming' where the main features of lifetime health outcomes are determined during pregnancy and the first year of life (Barker, 1991, 1994). In 'biological programming' "it is hypothesised that the individual can function only within the parameters set during this unique developmental opportunity" (during pregnancy and first year)(Wadsworth, 1997). Even though the importance of early development is now widely accepted, it is still too early to fully validate the 'biological programming' hypothesis. "It is not yet known whether such biological risk, apparently established early in life, is a source of vulnerability which necessarily requires a later life trigger, other than ageing, to activate its effects. Nor is it known how such early life effects interact with processes of ageing, nor with genetically defined risk" (Wadsworth, 1997). In addition, the probability of escaping from early determined parameters seem to differ with different aspects of health. For example, improvements in parental status raise the chance of height growth; but psychosocial processes seem less easy to escape (Wadsworth, 1997).

Birth spacing and birth order are additional biology related factors affecting child health. Generally firstborn children tend to have lower birth weight than subsequent births implying a non-linear relationship between mother's age at birth and child weight (Strauss and Thomas, 1995). Yassin (2000) found that mother's age at childbirth is negatively correlated to child mortality in Egypt. Birth spacing has a significant impact on child survival in Mali (Adams, Madhavan and Simon, 2002). But Yasin (2000) found that birth order and spacing have no significant impact on childhood mortality in Egypt.

In a large number of studies, parental education - particularly maternal education - has emerged as an important determinant of child health (Strauss and Thomas, 1995). King and Mascie-Taylor (2002) found a highly significant association between maternal education and height-for-age and weight-for-age z-scores of children in Papua New Guinea. Pfeiffer, Gloyd and Li (2001) showed that in Mozambique children grow better if mothers are more educated. Using data from the US, Brazil and Ghana, Thomas (1994) showed that while maternal education has a bigger impact on daughters, paternal education is more important for the health of sons. This result is 

robust even after controlling for household level fixed effects. Yassin (2000) found that both maternal and paternal education is equally important in reducing child mortality in Egypt. Generally, the importance of parental education declines when controls for infrastructure and community level heterogeneity are introduced (Strauss and Thomas, 1995; Desai and Alva, 1998). This indicates that parental education is partly reflecting better local services. Desai and Alva (1998), using information from 22 developing countries, show that the link between maternal education and child immunization remains strong but that between maternal education and infant mortality, children's height-for-age and immunization is weakened by the inclusion of community level variables for most of the countries. In the case of the Philippines, Bhargava (1994) found no significant effect of parental education on child health.

Most studies in child health so far do not control for parental characteristics in general and parental health in particular. Parental health is expected to have a positive impact on both income-earning capacity and child health. Part of the latter effect can be transmitted through sharing the same genetic pool. In addition, the capacity for childcare depends on the health of parents. Parental - particularly maternal - health has large effects on child health (for the US see Case, Lubotsky and Paxson, 2001; for the Philippines see Bhargava, 1994 and Persson, 2001). The exclusion of parental health biases the income coefficient in the form of unobserved heterogeneity; in Case, Lubotsky and Paxson (2001) the inclusion of parental health reduces the income coefficient but does not reduce it to zero.

A quick rundown of some other variables considered in the child health literature follows:

(a) Child health is affected by the structure of household. For example, children with lone parents - a growing phenomenon in industrialised countries - face a range of behavioural problems in the US. In addition, household food expenditure with a stepchild falls by around $5 \%$ as compared to that with a birth-child (Case and Paxson, 2001).

(b) Social networks can significantly affect child health. For example, Adams, Madhavan and Simon (2002) found that the size of different types of social networks in Mali increase the chances of child survival in Mali.

(c) Prices, particularly food prices, negatively affect child health. In Cote d'Ivoire, Thomas, Lavy and Strauss (1996) found significant effects of prices on child 

anthropometric outcomes. The study found that due to the relatively weak effect of income, a large amount of increase in income is needed to offset the negative effects of higher food prices. Martin-Prevel, et al. (2000) found that increased food prices following devaluation in the Congo have played an important part in undermining the nutritional status of children.

(d) Severity and frequency of infectious diseases limit child growth. As much as one-third of the faltering in growth in children in developing countries can be accounted for illness and diarrhoeal diseases (Orr, Dufour and Patton, 2001).

(e) Altitude potentially is an important determinant of health. Generally high altitudes are characterised by hypoxia (deficiency of oxygen), high solar radiation, cold, low humidity, wind, limited nutrition and rough terrain (Pawson, et al., 2001). Pawson, et al. (2001) studied two communities in Peru and were unable to isolate the effect of altitude; they argue that socio-economic conditions are more important than altitude in the areas they studied. An early study in Ethiopia (Clegg, et al., 1972) found that children in a highland community attain better anthropometric status than those in a lowland community. In addition to the relatively mild hypoxia in the highlands, the much higher incidence of infectious diseases in the lowland is an important reason for this finding.

(f) A more rounded study of health focusing on anthropometric outcomes has to examine the labour expenditures of individuals in addition to their nutritional intakes. Yamanaka and Ashworth (2002) studied the labour expenditures of girls and boys in rural Nepal. Girls were engaged in heavier tasks for longer hours than boys but they did not have poorer anthropometric status. Girls eat food considered to be of lower status but at the same time also energy-dense. In terms nutritional energy, girls fare better than boys compensating for heavier tasks.

The next section discusses some measurement issues and presents descriptive results as a prelude to the analytic work in Section 4.

\section{Measurement Issues and Some Descriptive Results}

Using anthropometric measurements have some advantages. (a) They are relatively easy to administer in the field and if carefully organised they can be pretty 
accurate. (b) Errors of measurement are likely to be random and hence are not correlated to the socio-economic characteristics of the sampled people. For example, self-assessment of health conditions may systematically be related to the socioeconomic characteristics of individuals (Strauss and Thomas, 1995). (c) They are less intrusive, for example, compared to interviewing people about sensitive health-related issues.

In this paper, the height-for-age z-scores of children that are ten years old or younger is used to measure their long-term health status. These z-scores are computed by comparing the heights of children with a certain standard that represents the heights of healthy children - currently the widely accepted standard is that of US healthy children.

Children's bodies respond to malnutrition and/or infection/disease in two ways and both can be identified by anthropometrics. In the short term, they lose weight and their body is wasted. This can be discerned by looking at their weight in relation to their height. If malnutrition and/or disease persist or result in long-term damage, children's growth decelerates (or ceases) resulting in low height-for-age or stunting (de Onis, 2000; Fernadez, Himes and de Onis, 2002). Differences in height growth are important indicators of differences in health status and they are intimately related to adult health risks (Wadsworth, 1997). In poor countries anthropometric outcomes are related to general health status (Thomas, Lavy and Strauss, 1996).

The importance of nutritional inputs and the disease environment for growth has been emphasised in the health literature. Ideas that some people can be 'small and healthy' are no more dominant. Experiences of children that faced a radically different nutritional and health environment as compared to their parents indicate that changes in nutrition and the health environment can significantly change height in a generation (Pawson, et al., 2001; Thomas, Lavy and Strauss, 1996; Bhandari, et al., 2002, etc.). For example, the growth of Indian children born to affluent households is the same as those in developed countries; but their parents fall short of that standard (Bhandari, et al., 2002).

In computing the height-for-age z-scores, the software Anthro developed by the Centers for Disease Control and Prevention (CDC) and World Health Organisation (WHO) is used. This software compares the heights of children in the sample with those of healthy American children at different ages. Due to the above-mentioned 

response of children's growth to changes in nutrition and the health environment using healthy American children as the standard is appropriate. ${ }^{3}$

Mistakes in measured height and the age of children are two sources of errors. These errors generate height-for-age z-scores that are either too low or too high. Anthro flags those observations that are either below -7 or above +7 . These observations are excluded.

\section{Figure 1: Histogram for Height-for-age Z-scores of Children with a Normal Curve}

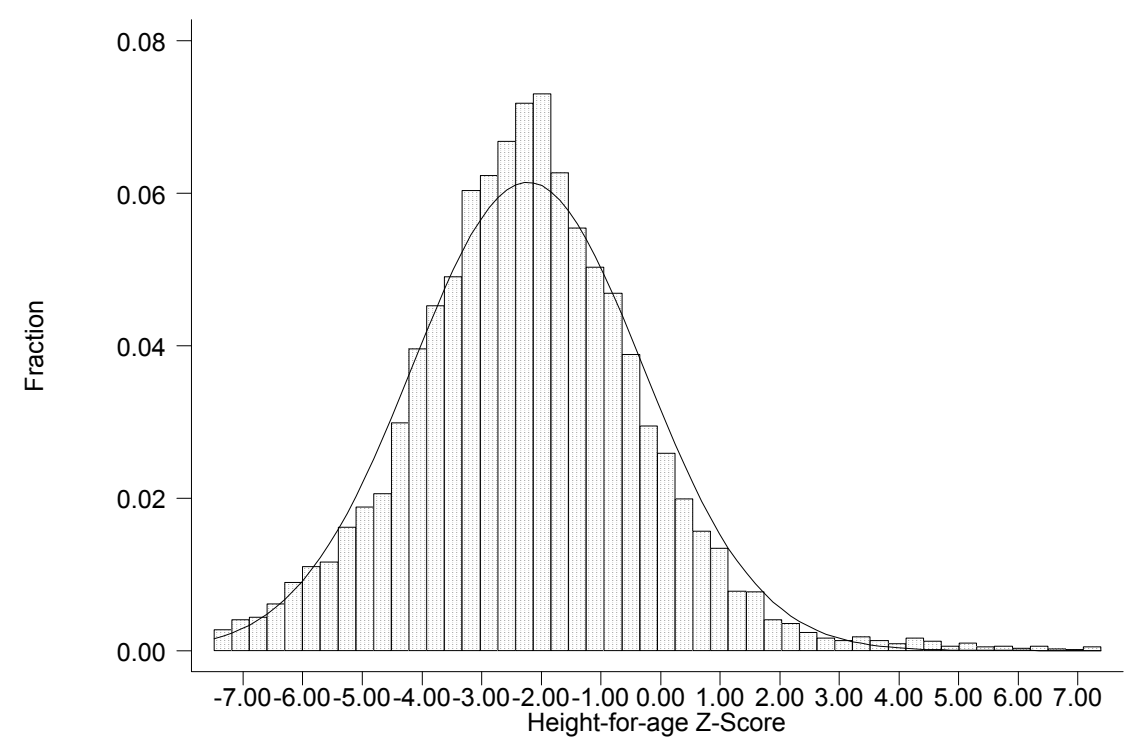

The average height-for-age z-score in the sample is -2.23 (median of -2.28). Since -2 is used as the cut-off point to identify stunted children, the result implies that the average rural child in Ethiopia is stunted. Around $56 \%$ of the children have heightfor-age z-scores below -2. Figure 1 gives the histogram of the height-for-age z-scores for the whole sample with a normal curve superimposed on it. The distribution is close to normal with the central mass shifted to the left - to negative values. The histograms for each survey village are very similar to the pooled one.

Figure 2 presents kernel regression of height-for-age z-scores on the (natural logarithm of) per capita expenditures with the $95 \%$ confidence interval. ${ }^{4}$ Even though a positive association generally seems to exist, over the range where the confidence band is tight the slope is more or less flat.

\footnotetext{
${ }^{3}$ See Bhandari, et al. (2002) for current efforts to create a new standard drawn from a sample of healthy children from different parts of the world.

${ }^{4}$ The kernel regression Stata programme used here is written by Marcel Fafchamps.
} 
Genetic Endowments, Parental and Child Health in Rural Ethiopia

Figure 2: Kernel Regression of Height-for-age Z-scores of Children on (natural logarithm of) Mean Per Capita Expenditures with 95\% Confidence Band

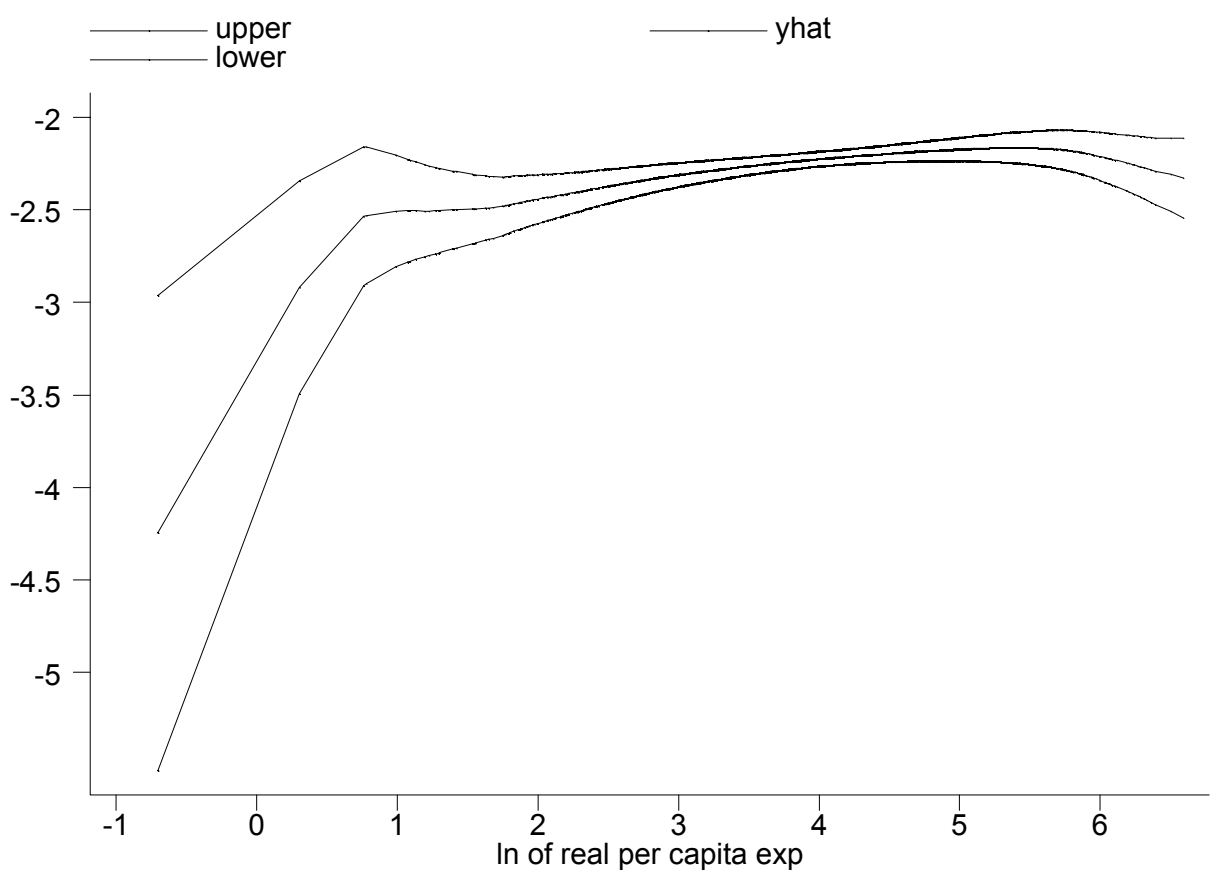

Figure 3: Kernel Regression of Height-for-age Z-scores on (natural logarithm of) Height of Household Head with $95 \%$ Confidence Band

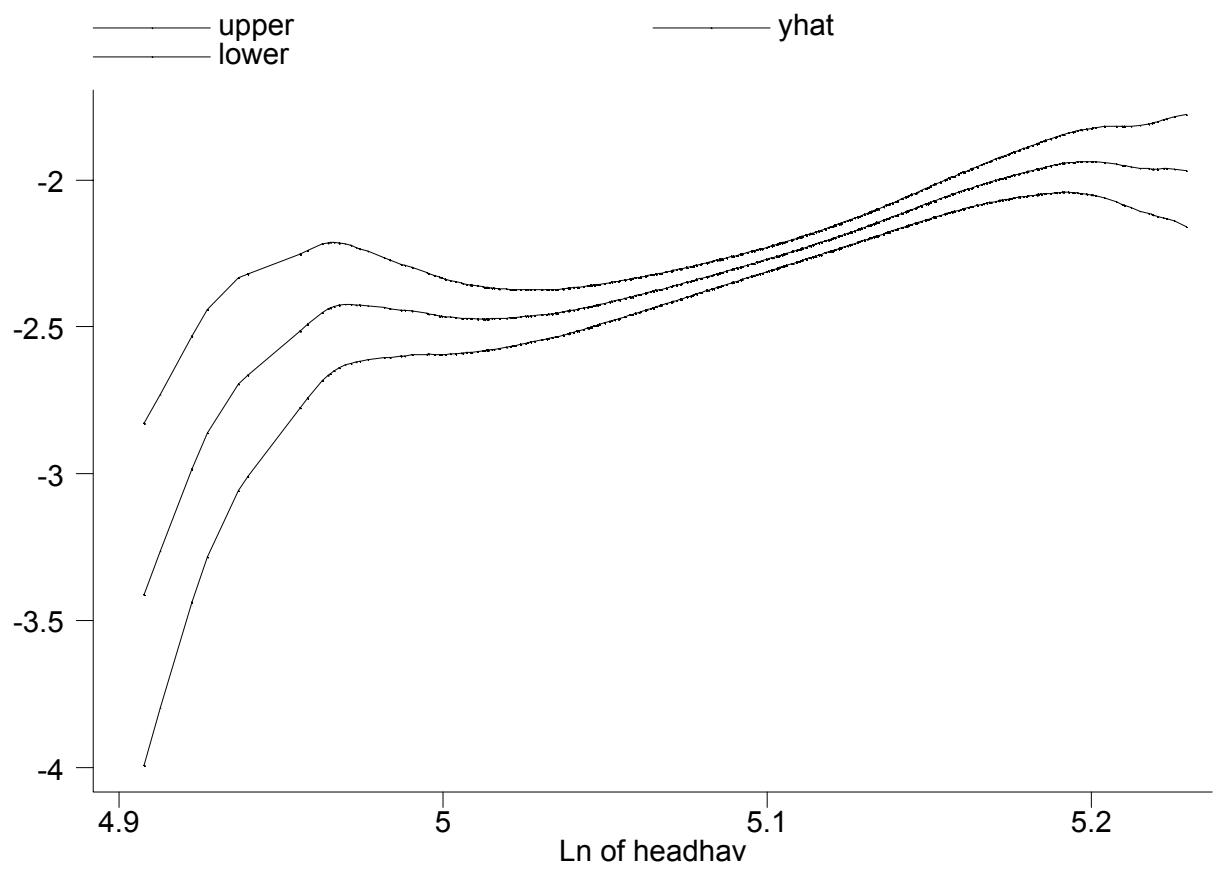


In addition to the influence of income this paper, unlike most previous studies, also examines the relationship of height-for-age z-scores of children with the height of their parents. Figure 3 presents the kernel regression of the height-for-age z-scores on the (natural logarithm of) height of the household head. A strong positive relationship seems to exist in the range with narrower confidence interval. This graph is steeper compared to the graph for per capita expenditures.

Table 1: Comparisons of Height and Height-for-Age Z-scores of Sampled Children with Results from Other Surveys

\begin{tabular}{|c|c|c|c|c|c|c|c|}
\hline \multicolumn{8}{|c|}{ Males: height (mean cm) } \\
\hline \multicolumn{2}{|l|}{ Age } & Sample & Peru (Marquiri) & Peru (Tintaya) & \multicolumn{3}{|c|}{ ) Ethiopia (Dellaportas) } \\
\hline $0-1$ & & 63.0 & & & & & \\
\hline $1-2$ & & 73.8 & & & & & \\
\hline $2-3$ & & 82.2 & & & & & \\
\hline $3-4$ & & 89.7 & & & & & \\
\hline $4-5$ & & 96.3 & 103.4 & 100.5 & & & \\
\hline $5-6$ & & 102.2 & 103.3 & 108.9 & & & \\
\hline $6-7$ & & 108.2 & 110.3 & 115.9 & & 112.4 & \\
\hline $7-8$ & & 114.2 & 115.6 & 118.8 & & 114.7 & \\
\hline $8-9$ & & 118.6 & 119.8 & 123.9 & & 120.1 & \\
\hline $9-10$ & & 123.0 & 122.3 & 130.0 & & 123.9 & \\
\hline \multicolumn{8}{|c|}{ Females: height (mean cm) } \\
\hline \multicolumn{2}{|l|}{ Age } & Sample & Peru (Marquiri) & Peru (Tintaya) & \multicolumn{3}{|c|}{ Ethiopia (Dellaportas) } \\
\hline $0-1$ & & 61.6 & & & & & \\
\hline $1-2$ & & \multirow{2}{*}{$\begin{array}{l}72.4 \\
80.7\end{array}$} & & & & & \\
\hline $2-3$ & & & & & & & \\
\hline $3-4$ & & 89.7 & & & & & \\
\hline $4-5$ & & 95.9 & 98.1 & 105.6 & & & \\
\hline $5-6$ & & 102.0 & 104.4 & 110.8 & & & \\
\hline $6-7$ & & 108.4 & 108.9 & 116.0 & \multicolumn{3}{|c|}{111.1} \\
\hline 7-8 & & 114.2 & 114.6 & 119.6 & \multicolumn{3}{|c|}{116.9} \\
\hline 8-9 & & 118.3 & 118.0 & 123.7 & & 122.5 & \\
\hline $9-10$ & & 122.0 & 124.4 & 130.3 & & 125.9 & \\
\hline & Males & & Mean hei & & & Females & \\
\hline Age group & Sample & Tukanoan & Achuar & Age & Sample & Tukanoan & Achuar \\
\hline $1.0-4.9$ & 85.65 & 86.1 & 85.3 & $1.0-4.9$ & 85.03 & 87.3 & 87.9 \\
\hline $5.0-9.9$ & 113.06 & 108.4 & 113.8 & $5.0-9.9$ & 112.14 & 108.6 & 110.2 \\
\hline & Males & & Mean height-for-a & e z-scores & & Females & \\
\hline Age & Sam & nple & ua NG & Age & & mple $\quad P$ & apua NG \\
\hline $0-2.9$ & -2 & 55 & 2.07 & $0-2.9$ & & 2.47 & -1.70 \\
\hline $3.0-5.9$ & -2 & 39 & 1.86 & $3.0-5.9$ & & 2.19 & -1.97 \\
\hline $6.0-11.9$ & -2 . & 13 & 2.94 & $6.0-11.9$ & & 1.85 & -3.36 \\
\hline
\end{tabular}

Source: Data on Marquiri and Tintaya tribes (Peru) from Pawson, et al. (2001), for Ethiopia (Dellaportas) from Dellaportas (1969), for Tukanoan and Achuar (American Indians) from Orr, et al. (2001) and for Papua New Guinea from King and Macie-Taylor (2002).

To have a comparative perspective and to check the reliability of the height measures, mean values from the sample are presented in Table 1 with measurements from other studies. All the results are drawn from rural communities. Generally, 

Ethiopian children are slightly shorter than both tribes from Peru. Compared to the two American Indian tribes, Ethiopian children are shorter at their early life (age of 15) generally overtaking them later (in the age group 5-10). The same pattern of relative improvement at latter ages (6-12 years) occurs in relation to children from Papua New Guinea. The figures for the sample of Ethiopian children surveyed in 1969 by Dellaportas are very similar to the figures from our sample (particularly for males). But overall there seems to be a slight decline over the years; at least the figures suggest that there are no improvements in the height of children. This reflects the stagnation in the economy and that rural children probably are as deprived as their counterparts some 25 years ago.

The kernel regressions above present the relationship between height-for-age zscores, per capita expenditures and parental height without controlling for other variables that may confound the relationship. A multivariate framework is required to control for the influence of other variables. In addition, controlling for heterogeneity at the community, household and individual levels is crucial to get an unbiased picture of the relationship between child health and the covariates. The next section tackles this problem.

\section{Estimation and Regression Results}

This section presents the main empirical results from the analysis of the determinants of child height-for-age z-scores. The first sub-section reports results from reduced form estimates of height-for-age z-scores for biological children of household heads. Parental health is controlled for in contrast to most previous studies on child health. The second sub-section focuses on the effect of genetic endowments on the correlation between the height of household heads and children's height-for-age Z-scores.

\subsection{Determinants of Long-term Child Health}

This sub-section focuses on analysing the determinants of long-term child health as reflected in height-for-age z-scores. Unlike most previous studies on child health, the correlations between children's height-for-age z-scores and community, household and individual level factors are examined by controlling for parental health as measured by height. This will help overcome one of the major limitations of many 
previous studies since parental health is expected to influence child health both through shared genetic endowments and behaviour.

Determinants of child health can be analysed either by estimating health production functions or reduced forms. In the former, direct inputs required for the production of child health are considered. Detailed information on nutrition including micronutrients - on medical inputs, etc. is required. In the reduced form, the ultimate impacts of exogenous factors net of the effects that work through inputs are identified (Strauss and Thomas, 1995; Thomas, Lavy and Strauss, 1996; Behrman and Deolalikar, 1989). In this paper, reduced forms of children height-for-age z-scores are estimated.

In both the health production function approach and reduced forms, fertility and mortality selections may become sources of bias. If the fertility behaviour of parents is influenced by the expected healthiness of their offspring, the distribution of the health of children will be systematically affected. For example, if parents expecting healthier children have more children compared to those expecting less healthy children, the average health status of children born will be biased upwards. In addition, if the less healthy die first, and hence will not be observed during survey periods, mortality selection will bias the health of surviving children upwards (see Strauss and Thomas, 1995; Pitt, 1997). Pitt (1997) estimated both fertility- and mortality-corrected reduced functions for Sub-Sahara African countries using the data from Demographic and Health Surveys. He found that most parameters are little changed when selection is accounted for.

The use of panel data and the estimation of individual-level fixed effects regressions help to control for fertility and mortality selection. Verbeek and Nijman (1992) show the conditions under which fixed and random effects estimators are not biased by selection. ${ }^{5}$ Consider the model of interest,

$$
y_{i t}=x_{i t} \beta+\alpha_{i}+\varepsilon_{i t}, i=1, \ldots, T ; i=1, \ldots, N
$$

$\mathrm{x}_{\mathrm{it}}$ is a vector of exogenous variables relating to the $\mathrm{i}^{\text {th }}$ cross sectional unit of period $\mathrm{t}$ and $\beta$ is a vector of unknown parameters of interest. In our case, $y_{i t}$, is the height-forage $\mathrm{z}$-scores of children and $\mathrm{x}_{\mathrm{it}}$ are correlates of child health. While $\alpha_{i}$ represent individual level (random or fixed) effects, $\varepsilon_{\text {it }}$ stands for random error.

\footnotetext{
${ }^{5}$ In addition to fertility and mortality, (survey) selection bias due to some children not observed over the whole panel period is also a source of bias, the technical nature of which is similar to the other two.
} 
Suppose $r_{i t}$ is an indicator variable that equals one if $y_{i t}$ is observed and zero otherwise. The selection criterion can be presented in a latent variable specification:

$$
\begin{gathered}
\mathrm{r}^{*}{ }_{\mathrm{it}}=\mathrm{z}_{\mathrm{it}} \gamma+\xi^{*}{ }_{\mathrm{i}}+\eta_{\mathrm{it}} \quad \mathrm{t}=1, \ldots, \mathrm{T} ; \mathrm{i}=1, \ldots, \mathrm{N} \\
\mathrm{r}_{\mathrm{it}}=1 \text { of } \mathrm{r}_{\mathrm{it}}>0 \text { and } \mathrm{r}_{\mathrm{it}}=0 \text { otherwise }
\end{gathered}
$$

$\mathrm{Z}_{\mathrm{it}}$ is a vector of exogenous variables - which can contain the same variables as $\mathrm{x}_{\mathrm{it}-}$ and $\xi_{i}$ are unobserved time-invariant individual-specific effects and $\eta_{\text {it }}$ unobserved random variable. In the case of fertility and mortality selection, the latent variable measures the inherent healthiness of children that affects whether the children are born in the first case or survive until the survey period in the second. Obviously, if selection is determined independent of $\alpha_{i}$ and $\varepsilon_{i t}$ the fixed effects estimator for $\beta$ will be unbiased and consistent. But this is too strong a condition. In our case, this implies that fertility and mortality selection is independent of the fixed health characteristics of children; obviously it is not.

Let $\tilde{\varepsilon}_{i t}$ be the error term from the regression of $y_{i t}$ on $x_{i t}$, both in deviations from their respective means. Verbeek and Nijman (1992) showed that a weaker and sufficient condition for unbiasedness and consistency of the fixed effects estimator exists. Independence of $r_{i}=\left(r_{i 1}, \ldots, r_{\mathrm{iT}}\right)^{\prime}$ and the transformed error term, $\tilde{\varepsilon}_{i t}$, also guarantee unbiased and consistent parameters.

$$
E\left\{\tilde{\varepsilon}_{i t} \mid r_{i}\right\}=0 ; t=1, \ldots, T ; i=1, \ldots, N
$$

Expression (3) does not contain the fixed effects, $\alpha_{\mathrm{i}}$. Hence, that selection depends on the individual effects does not introduce bias in the fixed effects estimator (Verbeek and Nijman, 1992; see also Baltagi, 1995, Vella, 1998). ${ }^{6}$

The use of panel fixed effects also helps to mitigate the problem of endogeneity in the covariates included. For example, unobserved child endowments in the disturbance may be correlated with parental endowments that affect the amount of household income (here, per capita expenditures). The fixed effects model is robust to the endogeneity of explanatory variables provided the fixed effect is the source of correlation (Blau, 1999). In addition, instrumental fixed effects regressions where per capita expenditures are instrumented by per capita land size cultivated by the household and the size of land owned by the parents of spouses are also estimated. ${ }^{7}$

\footnotetext{
${ }^{6}$ The random effects model requires a more stringent assumption to remain unbiased in the presence of selectivity (Verbeek and Nijman, 1992).

${ }^{7}$ Reverse causality in the first stage of the instrumental variable estimation (expenditures influencing land size) will not be a source of problem. First, even though the amount of land the household uses
} 
The latter will help to mitigate the problem of endogeniety if income is correlated to some unobservable variables that change over time and between children.

In the reduced forms estimated, in addition to income (per capita household expenditure used as proxy) the health of parents as measured by height is included. Height of parents is exogenous since it is determined by the time the children are born. Unobservable factors that affect children's height-for-age z-scores are independent of the height of parents as they occur during a period where adults' height has already been determined.

The reduced form equations are estimated by regressing height-for-age z-scores of children on different community, household and individual level covariates. The individual level fixed effects estimates are given in Tables 2 and 3. Information on 2,379 children of household heads with 6,025 observations over the four rounds of the survey (unbalanced panel) is used. Here, only children that are offspring of household heads are included; this enables us to examine some effects that are related only to biological children - birth order is an example. First, height-for-age z-scores are regressed on time-variant covariates (results given in Table 2). Then, the fixed effects estimated from the first stage are again regressed on time-invariant covariates (results given in Table 3). For the sake of comparison, the OLS, simple IV and individual random effects estimates are given in Appendix 1.

Heights of children are determined by resource availability over their whole lifetime and hence ideally all lagged levels of income should be considered. Per capita household expenditures are used since information on lagged income is not available. Household expenditures are better proxies of 'permanent' income as they are 'smoother' than income figures that usually fluctuate more. In addition the IV estimates use the household's and spouses' parents' land as instruments; this incorporates aspects of wealth and family background into the income measure to better reflect 'permanent' income.

will affect income, because land is owned and allocated by the state in Ethiopia income does not affect land size. Second, even though land size of parents can affect current wealth and expenditures of households, current expenditures cannot affect previous land holdings of parents. 
Table 2: Individual Fixed Effects Estimates of Height-for-Age z-scores of Children of Household Heads

\begin{tabular}{|c|c|c|c|c|}
\hline \multirow[t]{2}{*}{ Variable } & $\begin{array}{l}\mathrm{F}(21,3625)= \\
\text { Corr }\left(\mathrm{u}_{\mathrm{i}}, \mathrm{Xb}\right)= \\
\mathrm{u}_{\mathrm{i}}=0, \mathrm{~F}(2378, \\
0.0000 \\
\text { Sigma } \mathrm{u}=2.0 \\
\text { Rho }=0.8082\end{array}$ & $\begin{array}{l}\text { xed effects } \\
\text { ob }>F=0.0000 \\
7.96, \text { Prob }>F= \\
m a ~ e=0.9744\end{array}$ & $\begin{array}{l}\text { IV ind } \\
\text { Wald chi2 }(21, \\
0.0000 ; \text { Corr }( \\
\mathrm{u}_{\mathrm{i}}=0, \mathrm{~F}(2303, \\
0.0000 \\
\text { Sigma } \mathrm{u}=2.0 \\
\text { Rho }=0.7824\end{array}$ & $\begin{array}{l}\text { fixed effects } \\
8.40 ; \text { Prob }>\text { chi } 2= \\
=-0.2762 \\
=6.39, \text { Prob }>\text { F }= \\
\text { ma e }=1.0832\end{array}$ \\
\hline & Coefficient & Std. error & Coefficient & Std. error \\
\hline $\begin{array}{l}\text { Per capita exp. } \\
\text { Prices }\end{array}$ & 0.0006 & 0.0272 & 0.8083 & 0.7108 \\
\hline Maize price & 0.1809 & $0.0796 * *$ & 0.6658 & 0.4447 \\
\hline Barley price & 0.0874 & 0.0984 & 0.5001 & 0.3676 \\
\hline Sorghum & 0.1894 & $0.0738 * * *$ & 0.4019 & $0.2051 * *$ \\
\hline Teff price & 0.1181 & 0.1412 & 1.1743 & 0.9888 \\
\hline Wheat price & -0.2607 & $0.1523 *$ & -0.9233 & 0.5947 \\
\hline Millet price & 0.0536 & 0.0911 & 0.2593 & 0.1675 \\
\hline Horse beans & 0.1408 & 0.1051 & -0.3049 & 0.3833 \\
\hline Potato price & -0.2352 & $0.0511 * * *$ & -.01607 & $0.0763 * *$ \\
\hline Beef price & -0.0414 & 0.1014 & -0.0340 & 0.1170 \\
\hline Butter price & 0.0248 & 0.0558 & 0.2594 & 0.2206 \\
\hline Milk price & -0.0889 & $0.0513^{*}$ & 0.0541 & 0.1380 \\
\hline Egg price & -0.0852 & $0.0516^{*}$ & -0.1451 & $0.0742 * *$ \\
\hline Age & -0.2176 & $0.0689 * * *$ & -0.1771 & $0.0893 * *$ \\
\hline Age $\mathrm{x}$ famine & 0.1008 & 0.0963 & 0.0449 & 0.1205 \\
\hline Other children & 0.0069 & 0.0055 & 0.0212 & 0.0134 \\
\hline Adults & -0.1021 & 0.0840 & 0.0030 & 0.1760 \\
\hline $\begin{array}{l}\text { Yrs of } \\
\text { marriage }\end{array}$ & 0.0208 & $0.0071 * * *$ & 0.0352 & $0.0111 * * *$ \\
\hline Constant & -1.8587 & $0.4326 * * *$ & -6.9190 & 4.6141 \\
\hline
\end{tabular}

Note: All continuous variables are in natural logarithms. * Significant at 10\%; ** Significant at 5\%; *** Significant at $1 \%$.

Even though the coefficient for per capita expenditure (in natural logarithms) is significant for the OLS, it is not significant in both the random and fixed effects models. ${ }^{8}$ To examine whether household incomes affect the health of children in a non-linear fashion (as in Smith, 1999) households were classified into five per capita expenditure groups (quintiles) and dummy variables representing these quintiles were included in the regression. Even though the OLS results indicate that children from poorer households are shorter - similar to the concavity in Smith, 1999 - the parameters are not significant when individual effects are taken into account. This result reinforces the widespread suspicion in the literature that income coefficients are generally inflated in most studies because they do not control for individual heterogeneity that are correlated with income levels. Here, the fixed effects estimates

\footnotetext{
${ }^{8}$ In addition, average per capita expenditures - the mean per capita expenditures for the four survey rounds - were used as proxy to 'permanent' expenditures. Here also even though the OLS coefficient was significant, the coefficients from the other estimations were not.
} 
control not only for community and household heterogeneity but also those on the individual level.

In all specifications, the (natural logarithms of) height of the parent - who is household head - is highly significant and large. These results underscore the importance of controlling for parental health when studying child health. This strong correlation may operate either through sharing the same genetic endowments or through other influences - for example healthy parents may practice better childcare. The next sub-section will further look at genetic influences.

The inclusion of per capita expenditure and parental height in the same regression in the OLS and random effects regressions can result in collinearity since positive correlation between income and parental health is expected. To assess this possible problem, regressions dropping each one of the variables were estimated; the parameters were not significantly altered. In addition, the variance inflation factors were computed. The variance inflation factors for the whole regression as well as the individual variables are small; for example while the factor for the whole equation is 3.29 that for per capita expenditures and height of parents are 1.50 and 1.28 respectively. ${ }^{9}$

Child health is expected to be affected by prices of goods, particularly that of food items. Ideally, information on lagged prices of commodities over the whole lifetime of children should be considered to capture possible lagged impacts of prices. This information is not available and contemporaneous prices are used. As long as the relative prices of the goods remain more or less the same between survey villages, the current prices will reflect long-term relative costs of food in the different regions of the country. And there is no reason to believe that relative prices have significantly changed over the period of the lifetime of the children between the survey villages. No radical changes in infrastructure, no major transformations in cropping patterns, etc. are discernible during the ten-year period considered.

The prices of maize, barley, sorghum, teff, wheat, millet, horse beans, potato, beef, butter, milk and eggs are included in the regressions. Most of the coefficients on prices are not significant in most of the specifications. This could be a result of the conflicting effects of price changes. Since the goods are produced by many of the

\footnotetext{
${ }^{9}$ While some say only variance inflation factors greater than 30 should be taken seriously, others argue for a lower figure of 10 (Stata Corporation, 2001). In our case both thresholds are significantly higher than the computed variance inflation factors.
} 

households in the sample a change in price would have conflicting effects. For example, even though an increase in price raises the opportunity cost of consuming the good (decreasing demand), the same price increase also improves the income of the household (increasing demand). This conflicting effect may be the reason behind the insignificance of most of the price coefficients. Focusing on the individual level fixed effects, the prices of sorghum, potato, milk and egg are significant. ${ }^{10}$ While the coefficients of sorghum price are positive, the rest are negative. It is interesting that the prices of potato, milk and egg, food items that are used to feed children, are negative and significant. The prices of food items mainly used for children have a negative impact on their long-term health.

Table 3: Regressions on Fixed Effects

\begin{tabular}{|c|c|c|c|c|}
\hline \multirow[t]{2}{*}{ Variable } & \multicolumn{2}{|c|}{$\begin{array}{l}\text { Fixed effects from individual fixed } \\
\quad \text { effects model } \\
\mathrm{F}(25,5449)=41.41 \\
\text { Prob }>\mathrm{F}=0.0000 \\
\text { R-squared }=0.1510 \\
\text { Root } \mathrm{MSE}=1.6615\end{array}$} & \multicolumn{2}{|c|}{$\begin{array}{l}\text { Fixed effects from IV individual } \\
\quad \text { fixed effects model } \\
\mathrm{F}(25,5192)=44.50 \\
\text { Prob }>\mathrm{F}=0.0000 \\
\mathrm{R} \text {-squared }=0.1618 \\
\text { Root } \mathrm{MSE}=1.7017\end{array}$} \\
\hline & Coefficient & Std. error & Coefficient & Std. error \\
\hline $\begin{array}{l}\text { Height of parent } \\
\text { Birth order }\end{array}$ & 4.7811 & $0.5741 * * *$ & 2.8612 & $0.5989 * * *$ \\
\hline First born & 1.2498 & $0.1658 * * *$ & 1.1253 & $0.1668 * * *$ \\
\hline Second born & 0.7853 & $0.1655^{* * *}$ & 0.6729 & $0.1660 * * *$ \\
\hline Third born & 0.5395 & $0.1684 * * *$ & 0.4905 & $0.1690 * * *$ \\
\hline Fourth born & 0.2705 & 0.1733 & 0.2417 & 0.1745 \\
\hline Fifth born & 0.2921 & 0.1878 & 0.2480 & 0.1904 \\
\hline Sex (male) & -0.1841 & $0.04531 * * *$ & -0.2053 & $0.0477 * * *$ \\
\hline Born in famine & 0.0594 & 0.1360 & 0.0954 & 0.1415 \\
\hline Head's siblings & 0.0029 & 0.0039 & -0.0013 & 0.0040 \\
\hline Wife's siblings & -0.0062 & $0.0025 * *$ & -0.0115 & $0.0027 * * *$ \\
\hline Primary ed-head & -0.3467 & $0.0812 * * *$ & -0.4050 & $0.0831 * * *$ \\
\hline Primary ed-wife & 0.1070 & 0.1632 & -0.1969 & 0.1644 \\
\hline Altitude & -1.1584 & $0.1240 * * *$ & -1.4176 & $0.1322 * * *$ \\
\hline Proximity to towns & 0.3364 & $0.0342 * * *$ & 0.3578 & $0.0350 * * *$ \\
\hline Constant & -18.7947 & $3.0951 * * *$ & -7.1419 & $3.2286^{* *}$ \\
\hline
\end{tabular}

Note: All continuous variables are in natural logarithms. * Significant at 10\%; ** Significant at 5\%; $* * *$ Significant at $1 \%$.

The first three birth order variables are highly significant in all specifications. The dummy variable for children with six and above birth order is omitted - is used as a reference. The coefficients for the fourth and fifth birth order are not significant for all models indicating that there are no significant differences in height-for-age z-scores after the fourth birth. But children of birth ranks of one to three have significantly higher height-for-age z-scores than those below. In addition, the coefficients

\footnotetext{
${ }^{10}$ In the simple fixed effects while maize is significant, it is no more so when using instruments. In the IV estimation the price of milk becomes significant at around $14 \%$.
} 

consistently decrease with birth order; while first-born children have around 1.1 higher z-scores than fourth and above born children, the values for second- and third-born children are higher by 0.7 and 0.5 respectively. Elder children are healthier as reflected by their height-for-age z-scores. This could be because of biological reasons. ${ }^{11}$ Or it could be a result of behaviour of parents. For example, parents may favour elder offspring in allocating household resources. Another possible reason is diseconomies in child upbringing; the more the number of children the lesser the resources allocated to each. This is reminiscent of the trade-off between quality and quantity of children. Since elder children in the household have lived with smaller number of children at least for some part of their life, the earlier higher amount of resource allocated to them may be reflected in their better health. To further examine if the presence of other children affects the height-for-age z-scores, the number of 'other' children in the household is added as a variable. Even though this is statistically significant in the OLS and random effects models, ${ }^{12}$ it is not so in the fixed effects models. The result suggests that the birth order effect may not be due to diseconomies of scale. The birth order effect can also be a result of a steady decline in household resources; if a household is impoverished over time those born later are born into a poorer household. The number of adults in the household also is not significantly correlated with height-for-age z-scores of children.

Given the strong interdependence between households in Ethiopia relatives, particularly those with close blood ties, are expected to share some of the households' resources. The number (natural logarithm) of siblings of the household head and spouses are included. Interestingly, while the number of siblings of the household head is not significant in all specifications that for the wife remains significant and negative even after controlling for individual level heterogeneity. Wives manage household work and food preparation. Presumably, siblings of wives have better access to food of the household and compete with children more than siblings of husbands. This is the probable reason for the above result since nutrition is an important determinant of height in addition to infections and diseases.

Both sex and age of children are important covariates. In all specifications female children have higher height-for-age z-scores than male children. For example,

\footnotetext{
${ }^{11}$ For instance, firstborns usually weigh less than children born subsequently (Strauss and Thomas, 1995). Are earlier born children compensating with height for their lower weight?

${ }^{12}$ In fact in the OLS and random effects the coefficients are positive suggesting the opposite.
} 

using the result from IV individual level fixed effects, the average shortfall in male children's height-for-age z-scores as compared to that of females' is 0.21 . This probably reflects the faster growth of females in earlier life. Dellaportas (1969) found that Ethiopian girls are taller than boys for the age range of 7-14 years after which boys surpass them. Since our sample includes children younger than 10 years, this is a plausible explanation.

Age negatively affects the height-for-age z-scores of children. Even though age is insignificant in the OLS and random effects models, it becomes highly significant in the individual fixed effects regressions. A one-year increase in age decreases height-for-age z-scores by 0.18 in the IV fixed effects estimate. Since young children are more vulnerable to environmental risks than babies the result probably indicates that children are more exposed to later day risks rather than pre- or peri-natal deprivations.

To further pursue the issue of the importance of deprivations in the earlier periods of the children's lifetime, the effect of shocks from drought during or around pregnancy on the long-term growth of children is examined. A dummy variable for children born in a year when the household suffered significant loss in harvest due to drought is included. If pre- and peri-natal deprivations have long lasting effect, children conceived or born during periods of food shortage are expected to be shorter negative coefficient on the dummy. In addition, an interactive term between age and the dummy variable is added. Both variables are not significant suggesting that children recover from pre- and peri-natal nutritional deprivations at least in terms of their height.

Contrary to the general consensus in the literature, completion of primary education by the household head is negatively correlated to the height-for-age z-scores of children and the primary education of the wife is not significant. In most studies when controls for community, household and individual level characteristics are included the coefficient on education decreases. ${ }^{13}$ The result reinforces the doubt in the recent literature on the validity of research results that show a strong impact of parental education on child health without controlling for community, household and individual level heterogeneity. ${ }^{14}$

\footnotetext{
${ }^{13}$ Bhargava (1994) is one of the studies that did not find significant correlation between parental education and health.

${ }^{14}$ See Desai and Alva (1998) for one of the studies that strongly express this doubt.
} 
In all specifications, the length of marriage in years (in natural logarithms) is positively and significantly correlated with height-for-age z-scores. Marriages that last longer indicate stability. Stable marriages that probably result from optimal matching in the marriage market seem to create better conditions that positively impact on children's long-term health.

In all specifications altitude, measured in (natural logarithm of) metres above sea level, has a negative and highly significant effect on children's height-for-age zscores. This is in contradiction to an earlier study done in Ethiopia (Clegg, et al., 1972). Clegg, et al. (1972) found that children in a highland community in rural Ethiopia attain better anthropometric status than those in a lowland community. Apart from comparing anthropometric status of children in highland and lowland communities, the study did not control for other confounding factors in a multivariate framework - it did not control for community, household and individual level heterogeneity. For example, that children living in the low land community have worse anthropometric status is explained by the increased incidence of infectious diseases and possibly the higher ambient temperature in the lowland community. In addition to controlling for the above mentioned type of community level heterogeneity - which in fact are controlled even in the OLS and random effects models by the village dummies - here the individual level fixed effects regressions also control for household and individual level heterogeneity. Hence, this study reflects the 'net' effect of altitude better than Clegg, et al. (1972). As mentioned previously, high altitudes are generally characterised by hypoxia (deficiency of oxygen), high solar radiation, cold, low humidity, wind, limited nutrition and rough terrain that are detrimental to the growth of children (Pawson, et al., 2001).

Finally, proximity to larger urban areas positively affects the height-for-age zscores of children. Distance to and the size of the nearby town influence the access of rural households to different urban amenities. The ratio of the population of the nearest town to its distance from the survey village is used to control for this effect. The coefficients on the natural logarithm of variable are highly significant and positive in all specifications. The proximity of villages to urban areas may have helped to improve the health status of children by providing better access to health facilities, improved supply of drugs and supplementary food.

Among other results presented above, a strong correlation between parental and 
child health in terms of height is observed. Previous studies have also found similar results (for the US see Case, Lubotsky and Paxson, 2001; for the Philippines see Bhargava, 1994 and Persson, 2001). As mentioned above, this correlation can be due to sharing common genetic endowments or to behavioural and other factors - for example, healthy parents taking better care of children. The next sub-section examines the importance of genetic endowments in the correlation between child and parental health.

\subsection{Genetic Endowments, Adult and Child Health}

The previous sub-section showed the existence of a strong link between parental and child health; but it did not examine how far genetics are important in that relationship. This sub-section focuses on this issue.

If genetic influences are important, the correlation between the heights of household heads and the height-for-age z-scores of children will be stronger the nearer the genetic link between them. For example, the correlation between the heights of household heads and the height-for-age z-scores of biological children will be stronger than with grandchildren.

So far only children that are offspring of the household head are considered in the regressions presented in sub-section 4.1. ${ }^{15}$ In this sub-section all children in the sample, both biological children and others, are used in the regressions to get variations in genetic links between household heads and children. First, individual and IV individual level fixed effects regressions of height-for-age z-scores on time-variant variables are run; the results are given in Appendix 2. Then the fixed effects from these regressions are again regressed on time-invariant covariates. In this second stage, dummy variables representing the relationship of the child to the household head are interacted to the height of the head - results give in Table 4. The coefficients of the other variables in both stages of regressions are not significantly different from the results in the previous sub-section.

The highest coefficient from the interactive terms for both estimates - simple and IV fixed effects - is that for siblings of the household head. This supports the idea that genetic influences are dominant. Siblings of the household head share the same

\footnotetext{
${ }^{15}$ Otherwise, the effect of some variables that are associated only with biological offspring would not have been examined - birth order is a case in point.
} 

genetic endowments as the household head. ${ }^{16}$ In the case of children, half of their genetic endowments come from the parent that is not the household head. In both specifications the coefficients for children are less than that for siblings. Tests of equality of the coefficients are strongly rejected; for the simple fixed effects with an Fstatistics of 43.54 and p-value of 0.0000 and for IV fixed effects with an F-value of 37.46 with p-value of 0.000 .

Table 4: Regressions of Individual Fixed Effects on Time-Invariant Variables with Interactive Terms between (natural logarithm of) Height of Household Head and Relationship with Head

\begin{tabular}{|c|c|c|c|c|}
\hline \multirow[t]{2}{*}{ Variables } & \multicolumn{2}{|c|}{$\begin{array}{l}\text { Fixed effects from individual } \\
\quad \text { fixed effects model } \\
F(25,6608)=26.00 \\
\text { Prob }>F=0.0000 \\
\text { R-squared }=0.0858 \\
\text { Root } \mathrm{MSE}=1.8271\end{array}$} & \multicolumn{2}{|c|}{$\begin{array}{l}\text { Fixed effects from IV individual } \\
\quad \text { fixed effects model } \\
\mathrm{F}(25,6267)=30.33 \\
\text { Prob }>\mathrm{F}=0.0000 \\
\mathrm{R} \text {-squared }=0.1018 \\
\text { Root } \mathrm{MSE}=1.8194\end{array}$} \\
\hline & Coefficient & Std. error & Coefficient & Std. error \\
\hline \multicolumn{5}{|c|}{ Height of head $\mathrm{x}$} \\
\hline Child & 0.0925 & $0.0197 * * *$ & 0.0786 & $0.0202 * * *$ \\
\hline Grand child & 0.0651 & $0.0258 * *$ & 0.0354 & 0.0262 \\
\hline Sibling & 0.3366 & $0.0410 * * *$ & 0.3160 & $0.0428 * * *$ \\
\hline Niece/nephew & 0.1692 & $0.0617 * * *$ & 0.1414 & $0.0620^{* *}$ \\
\hline Other relative & 0.2716 & $0.0537 * * *$ & 0.2493 & $0.0549 * * *$ \\
\hline Non relative & 0.2877 & $0.0619 * * *$ & 0.2794 & $0.0662 * * *$ \\
\hline Sex of child & -0.1880 & $0.0453 * * *$ & -0.2086 & $0.0463 * * *$ \\
\hline Born in famine & -0.1471 & 0.1434 & -0.1820 & 0.1405 \\
\hline Head's siblings & -0.0028 & 0.0034 & -0.0051 & 0.0034 \\
\hline Wife's siblings & -0.0050 & $0.0023 * *$ & -0.0092 & $0.0024 * * *$ \\
\hline Primary ed-head & -0.2798 & $0.0773 * * *$ & -0.3608 & $0.0786 * * *$ \\
\hline Primary ed-wife & -0.0271 & 0.1593 & -0.2626 & $0.1576^{*}$ \\
\hline Altitude & -0.6980 & $0.1144 * * *$ & -0.9435 & $0.1178 * * *$ \\
\hline Near big towns & 0.2012 & $0.0311 * * *$ & 0.2244 & $0.0310 * * *$ \\
\hline \multicolumn{5}{|c|}{ Site dummies omitted } \\
\hline Constant & 3.5903 & $0.8167 * * *$ & 5.2819 & $0.8394 * * *$ \\
\hline
\end{tabular}

In both estimates the coefficient for grandchildren is less than that of children. But tests for the equality of the two coefficients are not as strongly rejected. In the case of simple fixed effects the test for equality of coefficients is accepted with Fstatistics of 2.22 (p-value of 0.1360 ) and for the IV fixed effects with F-statistics of

\footnotetext{
${ }^{16}$ This assumes that the siblings have the same mother and father as the household head, which likely is true for most of the cases.
} 
5.40 (p-value of 0.0202). ${ }^{17}$ Hence, generally the coefficients for grandchildren are either equal or less than that of children. This result also supports the genetic story. Household heads share more genetic endowments with their children than with their grandchildren; hence the correlation between the heights of parents and children is either stronger or equal to that of their grandchildren.

In both estimations nieces and nephews have higher coefficients than children and grandchildren. But tests of equality in both cases show that they are not statistically different from each other; the corresponding F-statistics (and p-values) for the simple and IV individual fixed effects are $1.69(0.1937)$ and $1.13(0.2881)$. This also tallies with the genetic story. In terms of inherited genetic endowments, biological children and nieces/nephews are the same; half of their genetic endowments are obtained from the same grandparents - parents of the household head.

While the above-discussed coefficients neatly support a story based on the importance of genetic inheritance, it would be difficult to rationalise the results in behavioural terms. For instance, households are not expected to favour siblings over their own children.

If the above genetic argument is followed through, the correlation between the height-for-age z-scores of those categorised as 'other' relatives and heights of household heads is expected to be lower than that for biological children. But in both estimations the coefficients for 'other' relatives are higher than children; the respective F-statistics (and p-values) for simple and IV fixed effects models are $12.51(0.004)$ and 10.87 (0.0010). There is no information that can be used to classify the 'other' relatives into more refined categories; hence, how closely related these children are to the household head cannot be known. Unless some of the children - particularly siblings - have been misclassified as 'other' relatives, this finding casts a shadow of doubt on the genetic explanation.

The genetic explanation cannot predict anything in relation to the correlation of the height-for-age z-scores of children that are non-relatives and the heights of the household heads; the two are not genetically related. But it is probably surprising to find a highly significant positive correlation between the two. Tests for the equality of the coefficients for non-relatives and children show they are significantly different from each other; the respective F-statistics (and p-values) for the simple and IV fixed

\footnotetext{
${ }^{17}$ In the latter case, the null hypothesis of equality is accepted at $5 \%$ but rejected at $1 \%$.
} 
effects are $10.90(0.0010)$ and 9.99 (0.0016). Children that reside in the households and are not related to the household heads are servants, tenants/boarder or 'other' nonrelatives. Neither would one expect this group of children to get a more favoured treatment as compared to biological children nor their height-for-age z-scores be affected by allocations inside the households they currently reside in. But it is interesting to find a strong correlation between the health of non-relative children and household heads; if these children are recruited through the labour market the finding may imply that the labour market is matching healthy employers with healthy workers.

Even though the findings are mixed, most of the results in this sub-section support the importance of genetic effects in the relationship between child and parental health. This gives sense particularly in an environment, like rural Ethiopia, where the living conditions of parents and children have remained more or less the same. If radical changes in the nutritional status and disease environment of parents and children occur - like the children of well to do Indian families (see Bhandari, et al., 2002) - the influence of genetic effects, particularly on height, is expected to be weaker.

In addition the results underscore the importance of controlling for genetic endowments either by the use of fixed effects estimates or incorporating the health of parents into the analysis.

The next section concludes.

\section{Conclusions}

This paper examined factors that affect long-term child health in rural Ethiopia. Unlike most of the researches in the literature the use of panel data and the estimation of fixed effects models helped to control for individual level heterogeneity. In addition, also unlike most studies, parental health is controlled for. The results show, as expected, a very strong correlation between parental and child health.

A closer examination of the correlation between parental and child health reveals that generally the conduit of influence is genetic. In a condition where the nutritional and disease conditions of parents and children has not dramatically changed this is logical.

This paper highlights on the following methodological issues in the study of child health: 
Genetic Endowments, Parental and Child Health in Rural Ethiopia

1. Controlling for individual heterogeneity is crucial.

2. Incorporating parental health in the study of child health is important. This is particularly important in a situation where there are no radical economic and social transformations that clearly distinguish the growth environment of parents and children.

3. Incorporating variables that usually are not taken into account in economics but are considered to be important in other disciplines can help. Genetic inheritance and altitude are cases in point.

Future studies on child health should consider these dimensions. In addition, future data collection efforts should also consider generating data that helps incorporate these dimensions into the analysis.

\section{References}

Adams, A.M., S. Madhavan and D. Simon (2002), "Women's Social Networks and Child Survival in Mali" Social Science and Medicine, Vol. 54, pp. 165-178

Baltagi, B.H. (1995), Econometric Analysis of Panel Data, Chichester, New York, etc., John Wiley and Sons

Barker, D.J.P. (1991), Fetal and Infant Origins of Adult Disease, London, British Medical Journal

Barker, D.J.P. (1994), Mothers, Babies, and Disease in Later Life, London, British Medical Journal

Behrman, J.R. and A.B. Deolalikar (1989), "Nutrition and Health", in H. Chenery and T.N. Srinivasan, eds., Handbook of Development Economics, Vol. 1, Amsterdam, Elsevier

Benzeval, M. and K. Judge (2001), "Income and Health: The Time Dimension", Social Science and Medicine, Vol. 52, pp. 1371-1390

Bhandari, N., R. Bahl, S. Taneja, M. de Onis and M.K. Bhan (2002), "Growth Performance of Affluent Indian Children is Similar to that in Developed Countries", Bulletin of the World Health Organization, Vol. 80, Issue 3, pp.189-195

Bhargava, A. (1994), "Modelling the Health of Filipino Children", Journal of the Royal Statistical Society. Series A (Statistics in Society), Vol. 157, Issue 3, pp. 417-432

Blau, D.M. (1999), "The Effect of Income on Child Development", The Review of Economics and Statistics, Vol. 81, No. 2, pp. 261-276

Blau, D.M., D.K. Guilkey and B.M. Popkin (1996), "Infant Health and the Labor Supply of Mothers", The Journal of Human Resources, Vol. 31, No. 1, pp. 90-139

Case, A. and C. Paxson (2001), "Mothers and Others: Who Invests in Children's Health?", Journal of Health Economics, Vol. 20, pp. 301-328

Case, A., D. Lubotsky and C. Paxson (2001), "Economic Status and Health in Childhood: The Origins of the Gradient", National Bureau of Economic Research

CDC-WHO (1999), Anthro: Software for Calculating Anthropometry, developed by K.M. Sullivan and J. Gorstein WHO and CDC

Clegg, E.J., I.G. Pawson, E.H. Ashton and R.M. Flinn (1972), "The Growth of Children at Different Altitudes in Ethiopia", Philosophical Transactions of the Royal Society of London: Series B, Biological Sciences, Vol. 264, No. 864, pp. 403-437

Curtis, L.J., M.D. Dooley, E.L. Lipman and D.H. Feeny (2001), "The Role of Permanent Income and Family Structure in the Determination of Child Health in Canada", Health Economics, Vol. 10, pp. 287-302

de Onis, M. (2000), "Measuring Nutritional Status in Relation to Mortality", Bulletin of the World Health Organization, Vol. 78, No. 10, pp. 1271-1274 
Dellaportas, G.J. (1969), "Growth of Schoolchildren in Gondar Area, Ethiopia”, Human Biology, Vol. 41, No. 2, pp. 218-222

Dercon, S. and P. Krishnan (2000), "In Sickness and in Health: Risk Sharing within Households in Rural Ethiopia", Journal of Political Economy, Vol. 108, No. 4, pp. 688-727

Desai, S. and S. Alva (1998), "Maternal Education and Child Health: Is There a Strong Causal Relationship?", Demography, Vol. 35, No. 1, pp. 71-81

Diaz, M.D.M. (2002), "Socio-economic Health Inequalities in Brazil: Gender and Gender Effects", Health Economics, Vol. 11, pp. 141-154

Duflo, E. (2000), "Grandmothers and Granddaughters: The Effects of Old Age Pension on Child Health in South Africa", MIT Department of Economics Working Paper 00-05, Cambridge MA, MIT

Ettner, S.L. (1996), "New Evidence on the Relationship between Income and Health", Journal of Health Economics, Vol. 15, pp. 67-85

Fernandez, I.D., J.H. Himes and M. de Onis (2002), "Prevalence of Nutritional Wasting in Populations: Building Explanatory Models using Secondary Data", Bulletin of the World Health Organization, Vol. 80, No. 4, pp. 282-292

Haddad, L. and J. Hoddinott (1994), "Women's Income and Boy-Girl Anthropometric Status in the Cote d'Ivoire", World Development, Vol. 22, No. 4, pp. 543-553

Hautvast, J.L.A., A. Pandor, J. Bureman, J.J.M. Tolboom, N. Chishimba, L.A.H. Monnens and W.A. van Staveren (2000), "Nutritional Status of Breastfed Infants in Rural Zambia: Comparison of the National Center for Health Statistics Growth Reference Versus the WHO 12-month Breastfed Pooled Data Set", Bulletin of the World Health Organization, Vol. 78, No. 4, pp. 535-541

Henneberg, M., A. Schilitz and K.M. Lambert (2001), "Assessment of the Growth of Children and Physical Status of Adults in Two Aboriginal Communities in South Australia", American Journal of Human Biology, Vol. 13, pp. 603-611

Hines, A.M. (1996), "Targeting Children at Risk through Adult health and Social Services: An Analysis of Family and Environmental Risk Factors", Children and Youth Services Review, Vol. 18 , No. 7, pp. 603-620

Jensen, R.T. and K. Ritcher (2001), "Understanding the Relationship between Poverty and Children's Health", European Economic Review, Vol. 45, pp. 1031-1039

Kebede, B. (2003), "Intra-household Distribution of Expenditures in Rural Ethiopia: A Demand Systems Approach", CSAE Working Paper Series, CSAE WPS/2003-08

King, S.E. and C.G.N. Macie-Taylor (2002), "Nutritional Status of Children from Papua New Guinea: Associations with Socioeconomic Factors", American Journal of Human Biology, Vol. 14, pp. 659-668

Leung, S.F. and S. Yu (1996), "On the Choice between Sample Selection and Two-part Models", Journal of Econometrics, Vol. 72, pp. 197-229

Lindahl, M. (2002), "Estimating the Effect of Income on Health and Mortality using Lottery Prizes as Exogenous Source of Variation in Income", IZA Discussion Paper No. 442

Little, R.J.A. (1985), “A Note About Models of Selectivity Bias", Econometrica, Vol. 53, No. 6, pp. 1469-1474

Lynch, J.W., G.A. Kaplan and J.T. Salonen (1997), "Why do Poor People Behave Poorly? Variation in Adult Health Behaviour and Psychosocial Characteristics by Stages of the Socioeconomic Lifecourse", Social Science and Medicine, Vol. 44, No. 6, pp. 809-819

Manning, W.G. and J. Mullahy (1999), "Estimating Log Models: To Transform or not to Transform?", NBER Technical Working Paper 246, Cambridge MA, NBER

Martin-Prevel, Y., F. Delpeuch, P. Traissac, J.-P. Massamba, G.Adoua-Oyila, K. Coudert and S. Treche (2000), "Deterioration in the Nutritional Status of Young Children and Their Mothers in Brazaville, Conge, Following the 1994 Devaluation of the CFA Franc", Bulletin of the World Health Organization, Vol. 78, No. 1, pp. 108-118

McMunn, A.M., J.Y. Nazroo, M.G. Marmot, R. Boreham and R. Goodman (2001), "Children's Emotional and Behavioural Well-being and the Family Environment: Findings from the Health Survey for England", Social Science and Medicine, Vol. 53, pp. 423-440

Mullahy, J. (2000), "Live Long, Live Well: Quantifying the Health of Heterogenous Populations", 
NBER Working Paper 7895, Cambridge MA, NBER

Orr, C.M., D.L. Dufour and J.Q. Patton (2001), "A Comparison of Anthropometric Indices of Nutritional Status in Tukanoan and Achuar Amerindians", American Journal of Human Biology, Vol. 13, pp. 301-309

Pawson, I.G., L. Huicho, M. Muro and Alberto Pachero (2001), "Growth of Children in Two Economically Diverse Peruvian High-Altitude Communities", American Journal of Human Biology, Vol. 13, pp. 323-340

Persson, T.H. (2001), "Women's Health Choices and the Effects on Child Health", Department of Economics, Lund University, Sweden, Mimeo

Pfeiffer, J., S. Gloyd and L.R. Li (2001), "Intrahousehold Resource Allocation and Child Growth in Mozambique: An Ethnographic Case-Control Study", Social Science and Medicine, Vol. 53, pp. 83-97

Pitt, M.M. (1997), "Estimating the Determinants of Child Health When Fertility and Mortality are Selective", The Journal of Human Resources, Vol. 32, No. 1, pp. 129-158

Shetty, P.S. and W.P.T. James (1994), Body Mass Index- A Measure of Chronic Energy Deficiency in Adults, Rome, Food and Agricultural Organization of the United Nations

Skoufias, E. (1998), "Determinants of Child Health During the Economic Transition in Romania". World Development, Vol. 26, No. 11, pp. 2045-2056

Smith, J.P. (1999), "Healthy Bodies and Thick Wallets: The Dual Relation Between Health and Economic Status", Journal of Economic Perspectives, Vol. 13, No. 2, pp. 145-166

Smith, S.C. (2002), "Village Banking and Maternal and child Health: Evidence from Ecuador and Honduras", World Development, Vol. 30, No. 4, pp. 707-723

Stata Corporation (2001), Stata Reference Manual-Release 7, College Station, Texas, Stata Press

Strauss, J., and D. Thomas (1995), "Human Resources: Empirical Modeling of Household and Family Decisions" in J.R. Behrman and T.N. Srinivasan, eds., Handbook of Development Economics IIIA, Amsterdam, Elsevier

Strauss, J., P.J. Gertler, O. Rahman and K. Fox (1993), "Gender and Life-Cycle Differentials in the Patterns and Determinants of Adult Health", The Journal of Human Resources, Vol. 28, No. 4, pp. 791-837

Suwal, J.V. (2001), "The Main Determinants of Infant Mortality in Nepal", Social Science and Medicine, Vol. 53, pp. 1667-1681

Teitler, J.O. (2001), "Father Involvement, Child Health and Maternal Health Behavior", Children and Youth Services Review, Vol. 23, No. 4/5, pp. 403-425

Thomas, D. (1994), "Like Father, Like Son: Like Mother, Like Daughter: Prenatal Resources and Child Height", The Journal of Human Resources, Vol. 29, No. 4, pp. 950-988

Thomas, D. and E. Frankenberg (2000), "The Measurement and Interpretation of health in Social Surveys", RAND Labor and Population Program Working Paper Series 01-06

Thomas, D., J. Strauss and M-H. Henriques (1990), "Child Survival, Height for age and Household Characteristics in Brazil", Journal of Development Economics, Vol. 33, pp. 197-234

Thomas, D., V. Lavy and J. Strauss (1996), "Public Policy and Anthropometric Outcomes in the Cote d'Ivoire", Journal of Public Economics, Vol. 61, pp. 155-192

Vella, F. (1998), "Estimating Models with Sample Selection Bias: A Survey", The Journal of Human Resources, Vol. 33, No. 1, pp. 127-169

Verbeek, M. and T. Nijman (1992), "Testing for Selectivity Bias in Panel Data Models", International Economic Review, Vol. 33, No. 3, pp. 681-703

Wadsworth, M.E.J. (1997), "Health Inequalities in the Life Course Perspective", Social Science and Medicine, Vol. 44, No. 6, pp. 859-869

Wooldridge, J.M. (1995), "Selection Corrections for Panel Data Models Under Conditional Mean Independence Assumptions", Journal of Econometrics, Vol. 68, pp. 115-132

Yamanaka, M. and A. Ashworth (2002), "Differential Workloads of Boys and Girls in Rural Nepal and Their Association with Growth", American Journal of Human Biology, Vol. 14, pp. 356-363

Yassin, K.M. (2000), "Indices and Sociodemographic Determinants of Childhood Mortality in Rural Upper Egypt", Social Science and Medicine, Vol. 51, pp. 185-197 
Appendix

Appendix 1: OLS, IV and Individual Random Effects Estimates of Height-for-Age z-scores of Children of Household Heads

\begin{tabular}{|c|c|c|c|c|c|c|c|c|}
\hline \multirow[t]{2}{*}{ Variable } & $\begin{array}{l}\mathrm{F}(46,5428)= \\
\text { Prob }>\mathrm{F}=0 . \\
\text { R-squared }= \\
\text { Root MSE }\end{array}$ & $\begin{array}{l}S \\
5.69 \\
00 \\
1056 \\
8093\end{array}$ & $\begin{array}{l}\mathrm{F}(46,5171) \\
\text { Prob }>\mathrm{F}=0 \\
\text { R-squared }= \\
\text { Root } \mathrm{MSE}=\end{array}$ & $\begin{array}{l}J \\
14.96 \\
00 \\
1035 \\
8141\end{array}$ & $\begin{array}{l}\text { Individual } \\
\text { Wald chi2 }(4 \\
\text { Prob }>\text { chi } 2 \\
\text { Sigma } \mathrm{u}=1 \\
\text { Sigma e }=0 \\
\text { Rho }=0.749\end{array}$ & $\begin{array}{l}\text { ldom effects } \\
=3978.16 \\
.0000 \\
44 \\
45\end{array}$ & $\begin{array}{l}\text { IV individu } \\
\text { Wald chi2 }(46 \\
\text { Prob }>\text { chi } 2= \\
\text { Sigma } \mathrm{u}=1 . \\
\text { Sigma e }=1 . \\
\text { Rho }=0.3942\end{array}$ & $\begin{array}{l}\text { andom effects } \\
50.57 \\
000\end{array}$ \\
\hline & Coefficient & Std. error & Coefficient & Std. error & Coefficient & Std. error & Coefficient & Std. error \\
\hline Per capita exp. & 0.0701 & $0.0359 * *$ & 0.2029 & 0.4352 & 0.0152 & 0.0264 & 0.3943 & 0.5322 \\
\hline $\begin{array}{c}\text { Height of parent } \\
\text { Prices }\end{array}$ & 4.5494 & $0.6181 * * *$ & 4.1003 & $1.1297 * * *$ & 4.5935 & $0.9789 * * *$ & 3.6568 & $1.4004 * * *$ \\
\hline Maize price & 0.1759 & 0.1333 & 0.2494 & 0.2978 & 0.1697 & $0.0817 * *$ & 0.3950 & 0.3536 \\
\hline Barley price & -0.0048 & 0.1746 & 0.0483 & 0.2757 & 0.0604 & 0.1014 & 0.2019 & 0.2834 \\
\hline Sorghum price & 0.1550 & 0.1342 & 0.1891 & 0.1728 & 0.2128 & $0.0757 * * *$ & 0.2716 & $0.1649 *$ \\
\hline Teff price & 0.2815 & 0.2302 & 0.3985 & 0.6381 & 0.2719 & $0.1419 *$ & 0.6961 & 0.7377 \\
\hline Wheat price & -0.2692 & 0.2579 & -0.3780 & 0.3996 & -0.3565 & $0.1572 * *$ & -0.5964 & 0.4145 \\
\hline Millet price & -0.0070 & 0.1522 & 0.0180 & 0.1669 & 0.0452 & 0.0918 & 0.0960 & 0.1467 \\
\hline Horse beans prc & 0.2010 & 0.1791 & 0.1159 & 0.3014 & 0.1225 & 0.1058 & -0.0501 & 0.3143 \\
\hline Potato price & -0.1999 & $0.0963 * *$ & -0.1835 & $0.0989 *$ & -0.2259 & $0.0537 * * *$ & -0.1898 & $0.0726 * * *$ \\
\hline Beef price & -0.1051 & 0.1808 & -0.1444 & 0.1860 & -0.0478 & 0.1058 & -0.0959 & 0.1389 \\
\hline Butter price & -0.0302 & 0.0965 & -0.0104 & 0.1629 & 0.0094 & 0.0568 & 0.0770 & 0.1740 \\
\hline Milk price & -0.1920 & $0.0947 * *$ & -0.1912 & 0.1291 & -0.1152 & $0.0546 * *$ & -0.0967 & 0.1277 \\
\hline $\begin{array}{l}\text { Egg price } \\
\text { Birth order }\end{array}$ & -0.1380 & 0.1025 & -0.1355 & 0.1093 & -0.0952 & $0.0525^{*}$ & -0.1366 & $0.0797^{*}$ \\
\hline First born & 0.8869 & $0.18312 * * *$ & 0.8750 & $0.1893 * * *$ & 1.0861 & $0.2086 * * *$ & 0.9516 & $0.1831 * * *$ \\
\hline Second born & 0.4838 & $0.1783 * * *$ & 0.4763 & $0.18461 * * *$ & 0.6914 & $0.2013 * * *$ & 0.5590 & $0.1762 * * *$ \\
\hline Third born & 0.3155 & $0.1775^{*}$ & 0.3393 & $0.1800^{*}$ & 0.4041 & $0.2010 * *$ & 0.3710 & $0.1690 * *$ \\
\hline Fourth born & 0.1390 & 0.1820 & 0.1594 & 0.1818 & 0.2349 & 0.2051 & 0.2160 & 0.1694 \\
\hline Fifth born & 0.2198 & 0.2013 & 0.2245 & 0.2011 & 0.2344 & 0.2253 & 0.2550 & 0.1860 \\
\hline Sex (male) & -0.1947 & $0.0494 * * *$ & -0.2292 & $0.0520 * * *$ & -0.1724 & $0.0778 * *$ & -0.2222 & $0.0616^{* * *}$ \\
\hline Age & 0.0103 & 0.0499 & 0.0082 & 0.0508 & -0.0572 & 0.0406 & -0.0053 & 0.0407 \\
\hline
\end{tabular}


Genetic Endowments, Parental and Child Health in Rural Ethiopia

\begin{tabular}{|c|c|c|c|c|c|c|c|c|}
\hline \multirow[t]{2}{*}{ Variable } & $\begin{array}{l}\mathrm{F}(46,5428)= \\
\text { Prob }>\mathrm{F}=0 . \\
\text { R-squared }= \\
\text { Root MSE }=\end{array}$ & $\begin{array}{l}\mathrm{LS} \\
5.69 \\
00 \\
1056 \\
.8093\end{array}$ & $\begin{array}{l}\mathrm{F}(46,5171) \\
\text { Prob }>\mathrm{F}= \\
\text { R-squared }= \\
\text { Root MSE = }\end{array}$ & $\begin{array}{l}V \\
14.96 \\
000 \\
1035 \\
.8141\end{array}$ & $\begin{array}{l}\text { Individual } \\
\text { Wald chi2 } \\
\text { Prob }>\text { chi2 } \\
\text { Sigma u }=1 \\
\text { Sigma e }=0 \\
\text { Rho }=0.749\end{array}$ & $\begin{array}{l}\text { idom effects } \\
=3978.16 \\
.0000 \\
44 \\
45\end{array}$ & $\begin{array}{l}\text { IV individ } \\
\text { Wald chi2 } 4 \\
\text { Prob }>\text { chi } 2= \\
\text { Sigma u }=1 . \\
\text { Sigma e }=1 . \\
\text { Rho }=0.394\end{array}$ & $\begin{array}{l}\text { andom effects } \\
50.57 \\
000\end{array}$ \\
\hline & Coefficient & Std. error & Coefficient & Std. error & Coefficient & Std. error & Coefficient & Std. error \\
\hline Born in famine & -0.1675 & 0.3052 & -0.1824 & 0.3107 & -0.2762 & 0.2119 & -0.1975 & 0.2563 \\
\hline Age $x$ famine & 0.2486 & 0.1968 & 0.2591 & 0.2025 & 0.1829 & 0.1446 & 0.1991 & 0.1788 \\
\hline Other children & 0.0206 & $0.0053 * * *$ & 0.0247 & $0.0094 * * *$ & 0.0128 & $0.0046 * * *$ & 0.0235 & $0.0102 * *$ \\
\hline Adults & 0.0297 & 0.0605 & 0.0436 & 0.0917 & 0.0150 & 0.0648 & 0.0773 & 0.1091 \\
\hline Head's siblings & 0.0043 & 0.0041 & 0.0024 & 0.0044 & -0.0007 & 0.0064 & -0.0013 & 0.0057 \\
\hline Wife's siblings & -0.0088 & $0.0028 * * *$ & -0.0104 & $0.0034 * * *$ & -0.0082 & $0.0042 * *$ & -0.0100 & $0.0038 * * *$ \\
\hline Primary ed-head & -0.2949 & $0.0877 * * *$ & -0.2584 & $0.1100 * *$ & -0.3183 & $0.1324 * *$ & -0.3005 & $0.1256^{* *}$ \\
\hline Primary ed-wife & 0.2192 & 0.1785 & -0.0059 & 0.1911 & 0.1016 & 0.2521 & -0.0544 & 0.2164 \\
\hline Yrs of marriage & 0.0241 & $0.0064 * * *$ & 0.0248 & $0.0067 * * *$ & 0.0345 & $0.0067 * * *$ & 0.0297 & $0.0067 * * *$ \\
\hline Altitude & -0.9636 & $0.1683 * * *$ & -0.8417 & $0.2320 * * *$ & -3.2729 & $0.5682 * * *$ & -0.6606 & $0.3126 * *$ \\
\hline Proximity to towns & 0.2897 & $0.0471 * * *$ & 0.1492 & $0.0741 * *$ & -0.1072 & 0.1041 & 0.2237 & $0.0640 * * *$ \\
\hline & & & Round & d site dummi & & & & \\
\hline Constant & -21.1022 & $3.4418 * * *$ & -19.3481 & $4.7288 * * *$ & - & - & -20.1908 & $5.9999 * * *$ \\
\hline
\end{tabular}

\footnotetext{
Note: All continuous variables are in natural logarithms. * Significant at $10 \% ; * *$ Significant at $5 \% ; * * *$ Significant at $1 \%$.

Appendix 1: OLS, IV and Individual Random Effects Estimates of Height-for-Age z-scores of Children of Household Heads (continued)
} 
Genetic Endowments, Parental and Child Health in Rural Ethiopia

Appendix 2: Individual Fixed Effects Regressions on Time-Variant Variables (all children)

\begin{tabular}{|c|c|c|c|c|}
\hline Variables & $\begin{array}{l}\text { Individua } \\
\mathrm{F}(21,4268)= \\
\text { Prob }>\mathrm{F}=0.0 \\
\text { Corr }(\mathrm{ui}, \mathrm{Xb})= \\
\text { Sigma } \mathrm{u}=2.1 \\
\text { Sigma e }=1.0 \\
\text { Rho }=0.8090 \\
\text { Coefficients }\end{array}$ & $\begin{array}{l}\text { ed effects } \\
3612 \\
33 \\
\text { Std. err }\end{array}$ & $\begin{array}{l}\text { IV fix } \\
\text { Wald chi2 }(21) \\
\text { Prob }>\text { chi } 2= \\
\text { Corr }(\text { ui, } \mathrm{Xb}) \\
\text { Sigma } \mathrm{u}=2.1 \\
\text { Sigma e }=1.1 \\
\text { Rho }=0.7877 \\
\text { Coefficients }\end{array}$ & $\begin{array}{l}\text { ffects } \\
549.73 \\
0 \\
390\end{array}$ \\
\hline \multicolumn{5}{|l|}{ Prices } \\
\hline $\begin{array}{l}\text { Maize price } \\
\text { Barley price } \\
\text { Sorghum price } \\
\text { Teff price }\end{array}$ & $\begin{array}{l}0.1150 \\
0.1072 \\
0.1704 \\
0.1607\end{array}$ & $\begin{array}{c}0.0799 \\
0.0957 \\
0.0734 * * \\
0.1400\end{array}$ & $\begin{array}{l}0.5058 \\
0.4252 \\
0.3910 \\
1.0464\end{array}$ & $\begin{array}{c}0.4615 \\
0.3739 \\
0.2302 * \\
1.0455\end{array}$ \\
\hline $\begin{array}{l}\text { Wheat price } \\
\text { Millet price } \\
\text { Horse beans pre } \\
\text { Potato price } \\
\text { Beef price } \\
\text { Butter price } \\
\text { Milk price } \\
\text { Egg price }\end{array}$ & $\begin{array}{c}-0.2879 \\
0.0043 \\
0.1152 \\
-0.2317 \\
-0.0028 \\
0.0403 \\
-0.0972 \\
-0.0343\end{array}$ & $\begin{array}{c}0.1483 * \\
0.0897 \\
0.1032 \\
0.0503 * * * \\
0.0996 \\
0.0553 \\
0.0500^{*} \\
0.0500\end{array}$ & $\begin{array}{c}-0.7549 \\
0.1631 \\
-0.3086 \\
-0.1923 \\
0.0349 \\
0.2733 \\
0.0327 \\
-0.0701\end{array}$ & $\begin{array}{c}0.5621 \\
0.1708 \\
0.4275 \\
0.0650 * * * \\
0.1200 \\
0.2445 \\
0.1495 \\
0.0699\end{array}$ \\
\hline $\begin{array}{l}\text { Per capita exp. } \\
\text { Age } \\
\text { Age x famine } \\
\text { Other children } \\
\text { Adults } \\
\text { Yrs of marriage }\end{array}$ & $\begin{array}{c}-0.0061 \\
-0.5910 \\
0.1674 \\
0.0087 \\
-0.0775 \\
0.0150\end{array}$ & $\begin{array}{c}0.0266 \\
0.0534^{* * *} \\
0.0942 * \\
0.0050^{*} \\
0.0818 \\
0.0068^{* *}\end{array}$ & $\begin{array}{c}0.6666 \\
-0.5288 \\
0.1257 \\
0.0178 \\
0.0034 \\
0.0249\end{array}$ & $\begin{array}{c}0.7582 \\
0.0640 * * * \\
0.1086 \\
0.0129 \\
0.1857 \\
0.0104 * *\end{array}$ \\
\hline \multicolumn{5}{|c|}{ Round dummies omitted } \\
\hline
\end{tabular}

